\title{
Chemical Composition and Larvicidal Activity of Lavandula angustifolia Subsp. angustifolia and Lavandula dentata Spp. dentata Essential Oils against Culex pipiens Larvae, Vector of West Nile Virus
}

\author{
Fouad El-Akhal, ${ }^{1}$ Amal Ramzi, ${ }^{2}$ Abdellah Farah, ${ }^{2}$ Yassine Ez Zoubi ${ }^{2},{ }^{2,3}$ \\ Moussa Benboubker, ${ }^{4}$ Khalid Taghzouti, ${ }^{5}$ and Abdelhakim El Ouali Lalami $\oplus^{1,2,6}$ \\ ${ }^{1}$ Regional Diagnostic Laboratory of Epidemiological and Environmental Health, Regional Health Directorate, \\ El Ghassani Hospital, Fez 30000, Morocco \\ ${ }^{2}$ Laboratory of Applied Organic Chemistry, Faculty of Sciences and Technology, University Sidi Mohammed Ben Abdellah, \\ Fez B P 2202, Morocco \\ ${ }^{3}$ Biotechnology, Environmental Technology and Valorization of Bio-Resources Team, Department of Biology, \\ Faculty of Sciences and Technologies Al-Hoceima, Abdelmalek Essaadi University, Tetouan, Morocco \\ ${ }^{4}$ Human Pathology Bio-Health and Environment Laboratory, Faculty of Medicine and Pharmacy, \\ Sidi Mohammed Ben Abdellah University, Fez, Morocco \\ ${ }^{5}$ Laboratory of Animal Physiology, Department of Biology, Faculty of Science, University Mohammed-V, Rabat, Morocco \\ ${ }^{6}$ Institute of Nursing Professions and Health Techniques of Fez, Regional Health Directorate, EL Ghassani Hospital, \\ Fez 30000, Morocco
}

Correspondence should be addressed to Abdelhakim El Ouali Lalami; eloualilalami@yahoo.fr

Received 24 April 2020; Revised 22 September 2020; Accepted 27 March 2021; Published 14 April 2021

Academic Editor: Cleber Galvão

Copyright ( $) 2021$ Fouad El-Akhal et al. This is an open access article distributed under the Creative Commons Attribution License, which permits unrestricted use, distribution, and reproduction in any medium, provided the original work is properly cited.

The Culex pipiens mosquito (Diptera: Culicidae) is highly suspected to be the vector responsible for the spread of several parasitic and viral diseases. The use of synthetic insecticides is generally the preferred method of controlling these mosquitoes' proliferation. However, it has led to resistance problems in target mosquitoes and environmental damage. Hence, diverse plant extracts could be considered as an alternative and potential source as mosquito control agents. In this study, essential oils of Lavandula angustifolia subsp. angustifolia and Lavandula dentata spp. dentata that are growing in Morocco were examined for their insecticidal effects on Culex pipiens larvae. The bioassay was performed according to a methodology inspired by the standard protocol of the World Health Organization. The mortality rate was determined after 24 hours of exposure, and probit regression analysis was used to calculate $\mathrm{LC}_{50}$ and $\mathrm{LC}_{90}$. The chemical analysis revealed that the principal compounds of $L$. angustifolia subsp. essential oils include linalool, linalyl acetate, geraniol, lavandulyl acetate, camphor, $\beta$-caryophyllene, terpinen- 4 -ol, $\beta$-myrcene, and 1,8-cineole, while the essential oil of $L$. dentata spp. was mainly composed of 1,8-cineole, camphor, $\alpha$-pinene, transpinocarveol, linalool, and borneol. These volatile compounds have shown a toxic effect against Culex pipiens larvae, with lethal concentrations $\mathrm{LC}_{50}$ and $\mathrm{LC}_{90}$ being, respectively, $140 \mu \mathrm{g} / \mathrm{ml}$ and $450 \mu \mathrm{g} / \mathrm{ml}$, for the L. angustifolia subsp. essential oil. Meanwhile, they were estimated at $2670 \mu \mathrm{g} / \mathrm{ml}$ and $7400 \mu \mathrm{g} / \mathrm{ml}$, respectively, for the $L$. dentata spp. essential oil. These results suggest using essential oils of two species of Lavandula to control the Culex pipiens mosquito. It could be useful for the study of new natural larvicidal compounds. 


\section{Introduction}

Culex are among the most important mosquito genera, well known for their public health interest [1]. Having a bloodsucking characteristic, Culex pipiens L. 1758 (Diptera: Culicidae) plays an important role in the transmission of arboviruses that infect humans, noting West Nile virus. Culex pipiens mosquito causes allergic responses that include local skin and systemic reactions such as angioedema and urticaria [2]. According to the WHO, the virus could cause fatal neurological disease in humans [3].

The prevention of these vector-borne diseases depends considerably on a program of vector control [4], with the WHO (2016) supporting the development of effective and sustainable vector control [5]. Thus, various approaches have been adopted [6], including the use of chemical, physical, and biological methods. Indeed, chemical methods are the most utilized to control Culex pipiens using synthetic chemicals with insecticidal properties [7]. Nevertheless, these chemicals have numerous negative effects; they cause damage to the environment, to other nontarget organisms, and to human health. Besides, the overuse of these substances induces mosquitoes' risk of developing resistance against the insecticides [8-10], which considerably reduces treatment effectiveness [11]. Therefore, the acute damage caused by synthetic insecticides has created the need to develop alternative approaches to control nasty mosquitoes [12], with minimized toxic effects on the environment and human health $[13,14]$.

It is recognized that the plant extracts contain a wide range of components that may have toxicity against insects through different larval and adult instars [15]. Generally, many researchers have been interested in essential oils as an environmentally important natural resource and as a new vector control agent [16]. Various studies had reported the effectiveness of essential oils against Culex mosquitoes, particularly those obtained from plant species belonging to the Lamiaceae family, used against Culex pipiens larvae $[17,18]$.

Therefore, in this study, essential oils extracted from L. angustifolia subsp. and L. dentata spp., which are growing in Morocco, were evaluated for their larvicidal action against Culex pipiens larvae. To our knowledge, the larvicidal activity of the Lavandula species on Culex pipiens larvae has not been previously documented in Morocco.

\section{Materials and Methods}

2.1. Plant Material. In this study, both Lavandula angustifolia subsp. angustifolia (L. angustifolia subsp.) and Lavandula dentata spp. dentata (L. dentata spp.) species were used for testing their larvicidal activity; they were collected between April and June 2017, from the region of Taounate, in the mountainous area, which is in the rural community of Timezgana (northeastern Morocco), at an altitude of approximately $800 \mathrm{~m}$. The specimens were deposited and stored in the Herbarium of the National Agency for Medicinal and Aromatic Plants in Taounate, Morocco.
2.2. Essential Oils' Extraction and Chemical Characterization. The essential oils (E. Oils) were extracted by hydrodistillation for 3 hours using a Clevenger device. The E. Oils were then dried on anhydrous sodium sulfate to remove residual water and stored in an opaque container at $4^{\circ} \mathrm{C}$ before use. The chemical characterization of E. Oils was carried out by gas chromatography coupled with mass spectrometry (GC-MS), which allows the identification of compounds according to their mass-to-charge ratio and to precisely quantify the composition of E. oils. The analytical chemical analysis was performed using a Hewlett-Packard instrument equipped with the HP1 fused silica column $(30 \mathrm{~m} \times 0.25 \mathrm{~mm}$, film thickness: $0.25 \mu \mathrm{m})$ and interfaced with a quadrupole detector (GC-quadrupole MS system, model 5970). The column temperature was programmed from 70 to $200^{\circ} \mathrm{C}$ at $10^{\circ} \mathrm{C} / \mathrm{min}$, and the injector temperature was $200^{\circ} \mathrm{C}$. Helium was used as the carrier gas with a flow rate of $0.6 \mathrm{ml} / \mathrm{min}$, and the mass detector operated at $70 \mathrm{eV}$.

2.3. Collection of Culex pipiens Larvae and Morphological Identification. Larvae of Culex pipiens mosquito were collected from a breeding site called Oued El-Mehraz (altitude: $423 \mathrm{~m} ; 34^{\circ} 02^{\prime} 13,74^{\prime \prime} \mathrm{N}$, and $4^{\circ} 59^{\prime} 59.279^{\prime \prime} \mathrm{W}$ ). This site is rich in organic substances, favoring overgrowth of the Culicidae species, especially Culex pipiens larvae. Larvae were collected using a rectangular plastic plate; they were then kept inside the breeding site at the same conditions with water temperature $22.6^{\circ} \mathrm{C} \pm 2{ }^{\circ} \mathrm{C}$ and relative humidity $70 \% \pm 5 \%$. Only mosquito larvae (fourth and third instars) were selected for experimental testing after a two-day rearing period, according to the recommendations of the WHO protocol. Morphological character larval identification was performed using the Moroccan identification key [19] of Culicidae and Mediterranean African mosquito identification software [20].

2.4. Larvicidal Bioassays. The larvicidal tests were conducted following a methodology inspired by the standard WHO protocol. Preliminary experiments were used to select a range of E. oil concentrations. For this purpose, the concentrations tested were as follows: 50, 100, 200, 400, and $800 \mu \mathrm{g} / \mathrm{ml}$ of L. angustifolia subsp. angustifolia and 1000, $2000,4000,8000$, and $16000 \mu \mathrm{g} / \mathrm{ml}$ of $L$. dentata spp. dentata using ethanol as the solvent. The test was performed by placing $1 \mathrm{ml}$ of each prepared suspension in a beaker containing previous $99 \mathrm{ml}$ of distilled water and twenty larvae at the 4th or final 3rd instar. A control test was simultaneously carried out by adding $1 \mathrm{ml}$ of ethanol to $99 \mathrm{ml}$ of distilled water placed in a beaker with twenty larvae. Three replicates were carried out for each of the larvicidal bioassays and the control assay. The percentage of mortality rate for all concentrations was determined after 24 hours of treatment.

If the mortality rate in the control is higher than $5 \%$, the mortality rate of the larvae exposed to the E. Oils must be corrected using Abbott's formula (1) [21]. If the control assay mortality exceeds $20 \%$, the test is invalid and should be repeated. 
$\%$ mortality corrected $=\left[\frac{\% \text { mortality observed }-\% \text { mortality control }}{100-\% \text { mortality control }}\right] \times 100$.

2.5. Statistical Processing of Data. The data were analyzed using probit analysis by software developed by CIRAD-CA/ MABIS [22]. The lethal concentration ( $\mathrm{LC}_{50}$ and $\mathrm{LC}_{90}$ ) values were obtained according to Finney's mathematical methods, with $95 \%$ confidence limits and by Chi2 test.

\section{Results}

3.1. Chemical Characterization. In our study, characterization by chemical analysis revealed that the E. Oil extracted from Lavandula species was mainly composed of compounds with terpene properties. From Table 1, it is clear that the main chemical components identified within L. angustifolia subsp. E. oils were linalool (32.23\%), linalyl acetate $(14.23 \%)$, geraniol (5.8\%), lavandulyl acetate (4.8\%), camphor (4.21\%), $\beta$-caryophyllene (4.2\%), terpinen-4-ol (3.4\%), $\beta$-myrcene $(2.75 \%)$, myrtenal $(2.62 \%), 1,8$-cineole $(2.25 \%)$, caryophyllene oxide (2.12\%), and borneol (2.01), whereas the L. dentata spp. E. Oil was mostly composed of 1,8 -cineole $(49.82 \%)$, camphor $(6.31 \%), \alpha$-pinene $(4.12 \%)$, trans-pinocarveol $(2.84 \%)$, linalool $(2.24 \%)$, and borneol (2.01\%).

3.2. Larval Mortality. After preliminary tests, Figures 1 and 2 present the effectiveness of E. Oils on Culex pipiens larvae after $24 \mathrm{~h}$ of exposure. As shown, both E. Oils showed significant larvicidal effect when tested against 4 th instar and late 3rd instar larvae of Culex pipiens. The mortality rate, expressed as a percentage, varies according to the concentrations of each E. Oil tested, which means that it was dose dependent. For L. angustifolia subsp. E. Oils (Figure 1), the highest mortality percentage (100\%) occurred at a concentration of $800 \mu \mathrm{g} / \mathrm{ml}$. Simultaneously, it was evaluated at $16000 \mu \mathrm{g} / \mathrm{ml}$ for $L$. dentata spp. E. Oils (Figure 2), versus the control results.

3.3. $L C_{50}$ and $L C_{90}$. According to Table 2 and Figures 1 and 3 , obtained $\mathrm{LC}_{50}$ and $\mathrm{LC}_{90}$ confirm the larvicidal activity of both $\mathrm{E}$. Oils tested. It can be seen that the L. angustifolia subsp. E.Oils have the lowest $\mathrm{LC}_{50}$ which was $140 \pm 0.1 \mu \mathrm{g} / \mathrm{ml}$ (70-200) and $\mathrm{LC}_{90}=450 \pm 0.05 \mu \mathrm{g} / \mathrm{ml}(350-610)$. A larvicidal effect was also attributed to L. dentata spp. E. Oils with $\mathrm{LC}_{50} \quad 2670 \pm 0.07 \mu \mathrm{g} / \mathrm{ml} \quad(1750-3480)$ and $\mathrm{LC}_{90}$ $7400 \pm 0.05 \mu \mathrm{g} / \mathrm{ml}$ (5990-9870) (Figures 2 and 4). The Chisquare test was not significant at $5 \%$ for both $\mathrm{E}$. Oils, which means a good adjustment of the model.

\section{Discussion}

This study showed that the chemical composition of E. Oil extracted from $L$. angustifolia subsp. and L. dentata spp. was mainly composed of camphor, linalool, 1,8-cineole, linalyl acetate, and $\alpha$-pinene, belonging to the monoterpene fraction. L. angustifolia subsp. E. Oil's main compounds were linalool (monoterpenol: $32.23 \%$ ) and linalyl acetate (monoterpenic ester: $14.23 \%$ ). The high level of these two compounds was widely documented during the characterization of the E. Oil of this plant. Indeed, Smigielski et al. reported significant levels of linalool (26.50-34.70\%) and linalyl acetate (19.70-23.4\%) as major compounds of the E. Oil obtained from flowers and aerial parts of L. angustifolia subsp. from Poland [23]. Similarly, another study conducted in India showed the same results with slightly elevated levels of linalool (36.10\%) and linalyl acetate (19.90\%) as the main compounds [24]. de Rapper et al. also noted similar results but with a high level of linalyl acetate (36.70\%) followed by linalool $(31.40 \%)$ as the main compounds of the E. Oil of L. angustifolia subsp. from South Africa [25]. These studies also demonstrated the presence of other compounds in L. angustifolia subsp. E. Oil such as $\alpha$-terpineol, 1,8-cineol, geranyl acetate, terpinen-4-ol, bornyl acetate, and $\beta$-caryophyllene with a variation in their levels from one country to another. About the E. Oil of L. dentata spp. characterized in our study, the major compounds were 1,8-cineole (49.82\%) and camphor (6.31\%). Nevertheless, other studies revealed some differences in the chemical profile of this plant. Dris et al. reported that the main chemical constituents identified in the E. Oil content of the leaves of this plant were $\alpha$-terpinolene (51.13\%), camphor (13.43\%), and eucalyptol (3.62\%) [26]. Moreover, Martins et al. revealed that the E. Oil of $L$. dentata spp. from Brazil obtained by steam distillation of aerial parts was mainly composed of monoterpenes, with higher concentrations of eucalyptol (46.30\%), fenchone (15.80\%), camphor (15\%), limonene (3.20\%), and linalool (0.30\%) [27]. In climatic conditions similar to our country, a recent study conducted by Dammak et al. on the characterization of E. Oil extracted from the leaves of $L$. dentata spp. grown in northern Tunisia revealed the presence of camphor $(35.0 \pm 1.90 \%)$ and 1,8-cineole $(32.02 \pm 0.50 \%)$ as major compounds [28]. The differences in the relative amounts of some chemical substances may be related to several factors such as geographical and climatic factors, the physiological age of the plant, the genotype, the location and characteristics of the relief on the cultivated land, the harvest period, and the part of the plant used [27-29].

The results of the larvicidal activity showed that the E. Oil of $L$. angustifolia subsp. induced the highest percentage of toxicity $(100 \%)$ at a concentration of $800 \mu \mathrm{g} / \mathrm{ml}$, whereas the E. Oils of $L$. dentata spp. exerted high toxicity at $16000 \mu \mathrm{g} / \mathrm{ml}$. The values obtained for $\mathrm{LC}_{50}$ and $\mathrm{LC}_{90}$ were, respectively, between $140 \mu \mathrm{g} / \mathrm{ml}(70-200)$ and $450 \mu \mathrm{g} / \mathrm{ml}(350-610)$ for the E. Oil of L. angustifolia subsp. and $2670 \mu \mathrm{g} / \mathrm{ml}(1750-3480)$ and $7400 \mu \mathrm{g} / \mathrm{ml}(5990-9870)$ for the E. Oil of $L$. dentata spp. The observed variability in the chemical composition of these E. Oils, thanks to mixtures of components differentiated by the identity and quantity of the main constituents, could be responsible for their insecticidal efficacy and the variability of 
TABLe 1: Chemical composition of L. angustifolia subsp. and L. dentata spp. essential oils.

\begin{tabular}{|c|c|c|c|c|}
\hline Peak $N^{\mathrm{a}}$ & Compound & $\mathrm{RI}^{\mathrm{b}}$ & L. angustifolia subsp. (\%) & L. dentata spp. (\%) \\
\hline 1 & $\alpha$-Thujène & 931 & 0.09 & 0.11 \\
\hline 2 & $\alpha$-Pinene & 933 & 0.21 & 4.12 \\
\hline 3 & Camphene & 953 & 0.2 & 1.12 \\
\hline 4 & $\beta$-Pinene & 980 & 0.14 & 0.32 \\
\hline 5 & $\beta$-Myrcene & 991 & 2.75 & - \\
\hline 6 & $p$-Cymene & 1026 & 0.25 & 0.11 \\
\hline 7 & Limonene & 1031 & 0.62 & 0.41 \\
\hline 8 & 1,8-Cineole & 1033 & 2.25 & 49.82 \\
\hline 9 & Linalool oxide E & 1075 & 0.9 & 1.32 \\
\hline 10 & Fenchone & 1078 & 0.21 & 0.74 \\
\hline 11 & Linalool & 1098 & 32.23 & 2.24 \\
\hline 12 & $\alpha$-Campholenal & 1125 & 0.14 & 0.25 \\
\hline 13 & trans-Pinocarveol & 1139 & 1.25 & 2.84 \\
\hline 14 & cis-Verbenol & 1142 & 0.12 & 0.32 \\
\hline 15 & Camphor & 1143 & 4.21 & 6.31 \\
\hline 16 & Lavandulol & 1148 & 1.6 & - \\
\hline 17 & Terpinen-4-ol & 1155 & 3.4 & $\operatorname{Tr}$ \\
\hline 18 & Borneol & 1165 & 2.01 & 2.01 \\
\hline 19 & p-Mentha-1,3-dien-8-ol & 1172 & - & 0.20 \\
\hline 20 & cis-Pinocarvone & 1183 & 0.25 & 1.10 \\
\hline 21 & p-Cymen-8-ol & 1184 & 0.09 & 1.21 \\
\hline 22 & Cryptone & 1188 & 0.12 & 0.71 \\
\hline 23 & $\alpha$-Terpineol & 1189 & 0.92 & 0.43 \\
\hline 24 & Myrtenal & 1193 & 2.62 & 1.61 \\
\hline 25 & Myrtenol & 1194 & 1.44 & 1.62 \\
\hline 26 & Verbenone & 1204 & 0.85 & 0.25 \\
\hline 27 & trans-Carveol & 1217 & 0.09 & 0.27 \\
\hline 28 & Cuminaldehyde & 1239 & - & 0.25 \\
\hline 29 & Geraniol & 1241 & 5.8 & 0.22 \\
\hline 30 & Linalyl acetate & 1241 & 14.23 & 0.12 \\
\hline 31 & Carvone & 1242 & 0.06 & 0.44 \\
\hline 32 & Lavandulyl acetate & 1271 & 4.8 & 0.25 \\
\hline 33 & Geranyl acetate & 1359 & 1.7 & - \\
\hline 34 & $\beta$-Caryophyllene & 1405 & 4.2 & 0.58 \\
\hline 35 & $\beta$-Selinene & 1485 & - & 1.56 \\
\hline 36 & Caryophyllene oxide & 1581 & 2.12 & 1.57 \\
\hline 37 & $t$-Cadinol & 1616 & 1.6 & - \\
\hline 38 & $\beta$-Eudesmol & 1649 & 0.54 & 1.12 \\
\hline 39 & $\alpha$-Bisabolol & 1683 & 0.37 & 0.27 \\
\hline 40 & $\beta$-Bisabolol oxide $\mathrm{A}$ & 1744 & 0.33 & 0.22 \\
\hline
\end{tabular}

${ }^{\mathrm{a}}$ Number of a peak in the order of elution. ${ }^{\mathrm{b}}$ Components identified based on mass spectra and retention indices. $\operatorname{Tr}$ : trace $(<0.01 \%)$.

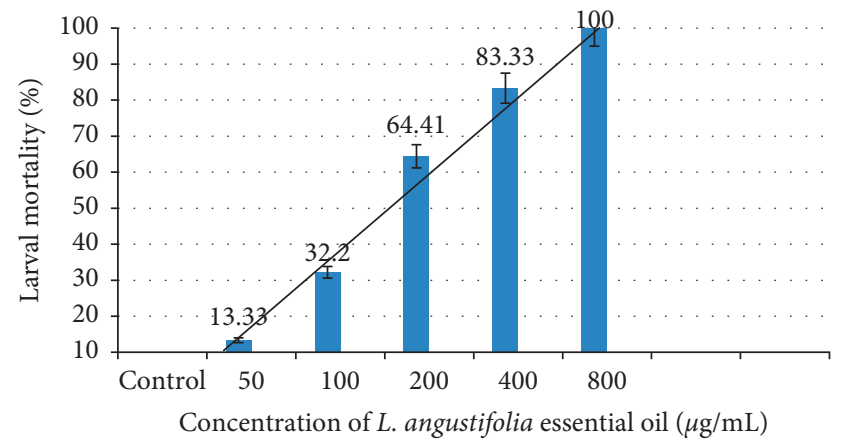

Figure 1: Mortality rate (\%) of Culex pipiens larvae according to the concentrations of $L$. angustifolia subsp. E. Oil after $24 \mathrm{~h}$ of exposure.

toxicity. However, the toxicity could also be attributed to the minor constituents or probably the synergistic effects of many chemical components [30,31].
Other researchers had revealed the larvicidal effect of L. angustifolia E. Oil and some of its chemical constituents. Indeed, Pavela [32] showed that E. Oils of L. angustifolia subsp. had larvicidal activity against Culex quinquefasciatus, with $\mathrm{LC}_{50}$ and $\mathrm{LC}_{90}$ at $121.60 \mu \mathrm{g} / \mathrm{ml}$ and $337.20 \mu \mathrm{g} / \mathrm{ml}$, respectively. Tabari et al. confirmed that linalool had a significant toxic effect on larvae and eggs of $C x$. pipiens with $\mathrm{LC}_{50}$ values of $14.87 \mu \mathrm{g} / \mathrm{ml}$ and $1.27 \mu \mathrm{g} / \mathrm{ml}$, respectively [33]. Other studies confirmed that linalol acetate had excellent larvicidal activity against $C x$. pipiens larvae with the $\mathrm{LC}_{50}$ value of $24.30 \mu \mathrm{g} / \mathrm{ml}$, while others confirmed its effectiveness against Aedes aegypti [34, 35]. Furthermore, a study conducted by Pavela Roman demonstrated an individual larvicidal effect of 30 compounds on Culex quinquefasciatus larvae. This study revealed that $\alpha$-pinene $\left(\mathrm{LD}_{50}=95 \mu \mathrm{g} / \mathrm{ml}\right)$ exerted a particular larvicidal influence compared to other terpene compounds, mainly 


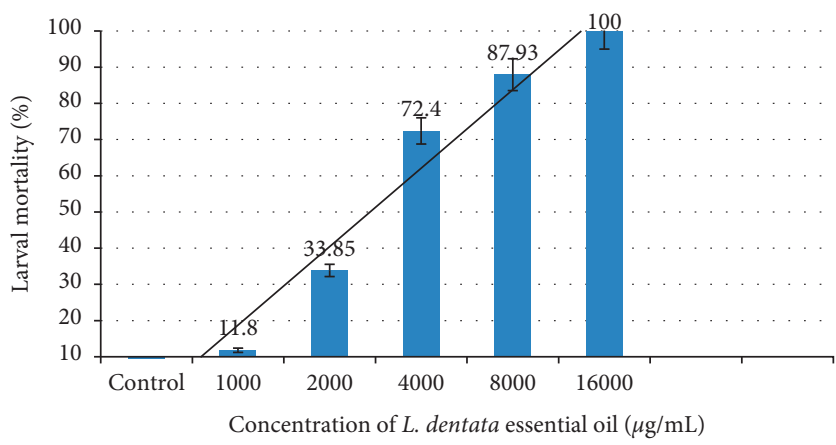

FIgURE 2: Mortality rate (\%) of Culex pipiens larvae according to the concentrations of $L$. dentata spp. E. Oil after $24 \mathrm{~h}$ of treatment.

TABLE 2: Lethal concentrations ( $\mathrm{LC}_{50}$ and $\mathrm{LC}_{90}$ ) of L. angustifolia subsp. E. Oils and L. dentata spp. E. Oils.

\begin{tabular}{lcccc}
\hline Plant species & The probit model: $a+b \cdot \log (\mathrm{dose})$ & $\mathrm{LC}_{50}(\mu \mathrm{g} / \mathrm{ml})(\mathrm{Ll}-\mathrm{Ul})^{*}$ & $\mathrm{LC}_{90}(\mu \mathrm{g} / \mathrm{ml})(\mathrm{Ll}-\mathrm{Ul})^{*}$ & Calculated Chi-square \\
\hline L. angustifolia subsp. & $Y=2.18341+2.60318^{*} X$ & $\begin{array}{c}140 \pm 0.1(70-200) \\
X=-8.38749 e-01\end{array}$ & $\begin{array}{c}450 \pm 0.05(350-610) \\
X=-3.46378 e-01\end{array}$ & 4.31 \\
\hline L. dentata spp. & $Y=-1.22979+2.87581^{*} X$ & $\begin{array}{c}2670 \pm 0.07(1750-3480) \\
X=5.92320 e-01\end{array}$ & $\begin{array}{c}7400 \pm 0.05(5990-9870) \\
X=1.15369 e+00\end{array}$ & 2.79 \\
\hline
\end{tabular}

${ }^{*} \mathrm{Ll}-\mathrm{Ul}$ : lower limit-upper limit; $\mathrm{LC}_{50}=$ lethal concentration that kills $50 \%$ of the exposed larvae; $\mathrm{LC}_{90}=$ lethal concentration that kills $90 \%$ of the exposed larvae.

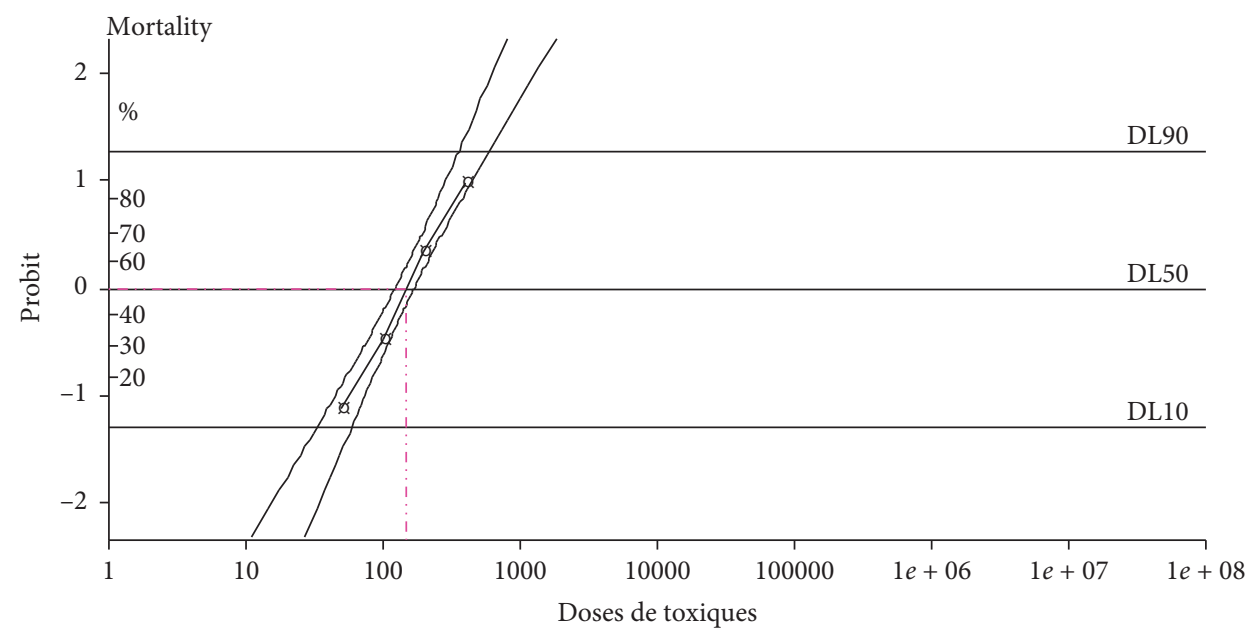

Figure 3: A graphic representation showing the $\mathrm{LC}_{50}$ and $\mathrm{LC}_{90}$ values of L. angustifolia subsp. E. Oil after $24 \mathrm{~h}$ of exposure.

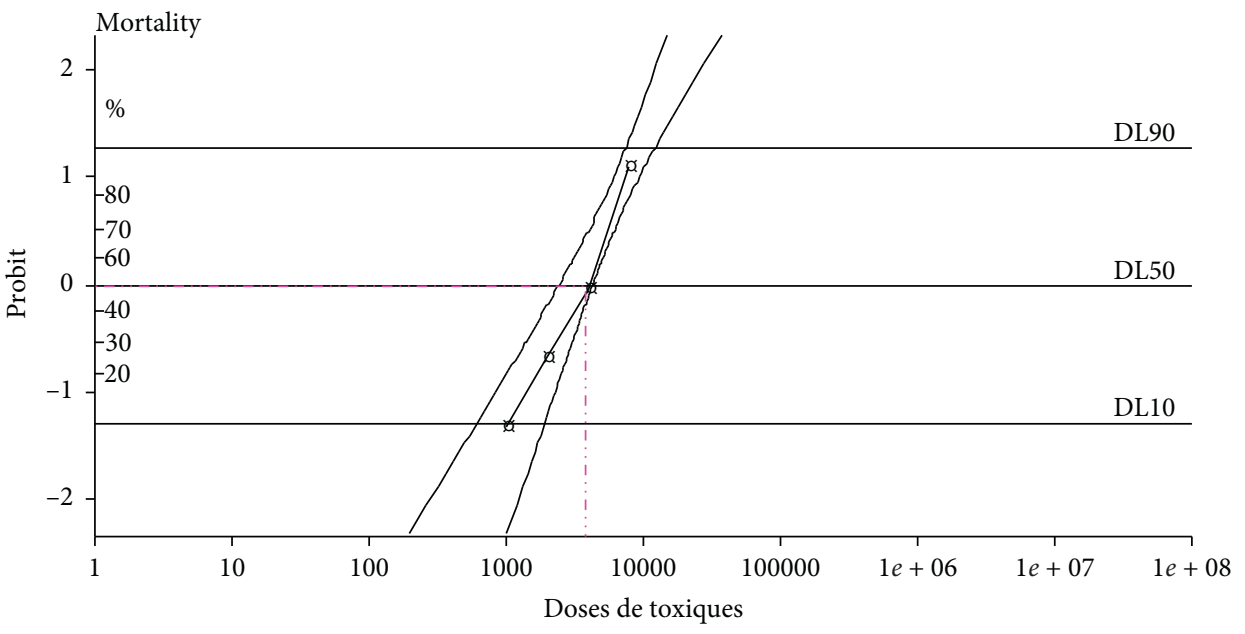

Figure 4: A graphic representation showing the $\mathrm{LC}_{50}$ and $\mathrm{LC}_{90}$ values of $L$. dentata spp. E. Oil after $24 \mathrm{~h}$ of exposure. 
detected in our study, in particular, 1,8-cineol, camphor, and borneol $\left(\mathrm{LD}_{50}>250 \mu \mathrm{g} / \mathrm{ml}\right)$ [36]. A synergistic binary effect had also been reported against Culex quinquefasciatus larvae between linalool and several terpene compounds identified in the E. Oil of L. angustifolia subsp. such as camphor, myrcene, borneol, and cineole [36]. E. Oil extracted from $L$. dentata spp. had also proven its larvicidal actions that could be explained by the high content of $\alpha$-terpinolene, camphor, and other compounds [26, 37]. Dris et al. noted that the E. Oil of $L$. dentata spp. from Algeria exerted a larvicidal effect against the fourth-instar larvae of Culex pipiens, and $\mathrm{LC}_{50}$ and $\mathrm{LC}_{90}$ values were estimated at $113.38 \mu \mathrm{g} / \mathrm{ml}$ and $150.38 \mu \mathrm{g} / \mathrm{ml}$, respectively [26].

The variability in the larvicidal efficacy of the E. Oils extracted from Lavandula specimens in our study and previous studies could be explained by the diversity of the chemical composition of each E. Oil, which is significantly influenced by climate, geographical origin, harvest, and mineral nutrition [38]. The commonalities presented by these studies are primarily to solve the problem of larval and insect resistance, to use these oils as an alternative to synthetic insecticides, and to provide their use in developing countries to control many mosquitoes [15].

\section{Conclusion}

The results obtained in this research showed that the essential oils extracted from $L$. angustifolia and $L$. dentata spp. growing in Morocco proved to be rich in promising larvicidal agents to fight against Culex pipiens larvae. As perspectives, further studies, taking into account the recommendations of the $\mathrm{WHO}$ about developing insecticides based on botanicals, are required on the synergistic effects and toxicity of essential oils' chemical components to optimize their larvicidal potential and to valorize these natural products as an important insecticidal alternative for the control of Culex species.

\section{Data Availability}

The data used in this study are included within the article.

\section{Conflicts of Interest}

The authors declare that they have no conflicts of interest.

\section{Authors' Contributions}

Fouad El-Akhal conducted larvicidal activity and statistical data analysis. Amal Ramzi interpreted the results obtained and drafted the manuscript. Yassine Ez Zoubi helped in English writing and rectification process. Mousa Benbouker and Khalid Taghzouti helped in the correction of English language, typographical errors, and grammar with text review and corrections. Abdelah Farah and Abdelhakim El Ouali Lalami contributed to the conception and design of the study and helped in the English writing of the manuscript. All authors read and approved the final manuscript.

\section{Acknowledgments}

The authors express special gratitude to everyone who has contributed to the success of this work. This research was carried out within the framework of the authors and their laboratories' activities.

\section{References}

[1] S. Senthil-Nathan, "A review of resistance mechanisms of synthetic insecticides and botanicals, phytochemicals, and essential oils as alternative larvicidal agents against mosquitoes," Frontiers in Physiology, vol. 10, pp. 1-21, 2020.

[2] S.-S. Cheng, C.-G. Huang, W.-J. Chen, Y.-H. Kuo, and S.-T. Chang, "Larvicidal activity of tectoquinone isolated from red heartwood-type Cryptomeria japonica against two mosquito species," Bioresource Technology, vol. 99, no. 9, pp. 3617-3622, 2008.

[3] WHO, Virus du Nil Occidental, WHO, Geneva, Switzerland, 2017, https://www.who.int/fr/news-room/fact-sheets/detail/ west-nile-virus.

[4] L. Yuan, X. Yang, X. Yu, Y. Wu, and D. Jiang, "Resistance to insecticides and synergistic and antagonistic effects of essential oils on dimefluthrin toxicity in a field population of Culex quinquefasciatus Say," Ecotoxicology and Environmental Safety, vol. 169, pp. 928-936, 2019.

[5] WHO, Global Vector Control Response 2017-2030, WHO, Geneva, Switzerland, 2016.

[6] A. L. Wilson, O. Courtenay, L. A. Kelly-Hope et al., "The importance of vector control for the control and elimination of vector-borne diseases," PLoS Neglected Tropical Diseases, vol. 14, no. 1, 2020.

[7] F. Z. Tmimi, C. Faraj, M. Bkhache et al., "Insecticide resistance and target site mutations (G119S ace-1 and L1014F kdr) of Culex pipiens in Morocco," Parasites and Vectors, vol. 11, no. 1, pp. 1-9, 2018.

[8] M. El Joubari, C. Faraj, A. Louah et al., "Sensibilité des moustiques Anopheles labranchiae, Culex pipiens, Ochlerotatus detritus et Ochlerotatus caspius de la région de Smir (Nord-Ouest du Maroc) aux organophosphorés utilisés en santé publique," Environnement, Risques \& Santé, vol. 14, no. 1, pp. 72-79, 2015.

[9] M. Bkhache, F. Z. Tmimi, O. Charafeddine et al., "First report of L1014F-kdr mutation in Culex pipiens complex from Morocco," Parasites and Vectors, vol. 9, no. 1, pp. 1-7, 2016.

[10] F. El-Akhal, M. Saâd, E. B. Adlaoui et al., "Resistance of Culex pipiens (Diptera: Culicidae) to organophosphate insecticides in Centeral Morocco," International Journal of Toxicological and Pharmacological Research, vol. 8, no. 4, pp. 263-568, 2016.

[11] J. M. Murugan, G. Ramkumar, and M. S. Shivakumar, "Insecticidal potential of Ocimum canum plant extracts against Anopheles stephensi, Aedes aegypti and Culex quinquefasciatus larval and adult mosquitoes (Diptera: Culicidae)," Natural Product Research, vol. 30, no. 10, pp. 1193-1196, 2016.

[12] Y. Ez zoubi, F. El-Akhal, A. Farah et al., "Phytochemical screening and larvicidal activity of Moroccan Ammi visnaga against larvae West Nile vector mosquito Culex pipiens (Diptera: Culicidae)," International Journal of Pharmacognosy and Phytochemical Research, vol. 8, no. 10, pp. 1684-1688, 2016.

[13] G. Ramkumar, S. Karthi, R. Muthusamy et al., "Mosquitocidal effect of glycosmis pentaphylla leaf extracts against three mosquito species (Diptera: Culicidae)," PLoS One, vol. 11, no. 7, pp. 1-11, 2016. 
[14] R. Pavela, F. Maggi, R. Iannarelli, and G. Benelli, "Plant extracts for developing mosquito larvicides: from laboratory to the field, with insights on the modes of action," Acta Tropica, vol. 193, pp. 236-271, 2019.

[15] P. Vivekanandhan, R. Venkatesan, G. Ramkumar et al., "Comparative analysis of major mosquito vectors response to seed-derived essential oil and seed pod-derived extract from Acacia nilotica," International Journal of Environmental Research and Public Health, vol. 15, no. 2, 2018.

[16] P. Vivekanandhan, S. Senthil-Nathan, and M. S. Shivakumar, "Larvicidal, pupicidal and adult smoke toxic effects of Acanthospermum hispidum (DC) leaf crude extracts against mosquito vectors," Physiological and Molecular Plant Pathology, vol. 101, pp. 156-162, 2018.

[17] F. El-Akhal, H. Greche, F. Ouazzani Chahdi et al., "Chemical composition and larvicidal activity on Culex pipiens of essential oil of Thymus vulgaris grown in Morocco," Journal of Materials and Environmental Science, vol. 6, no. 1, pp. 214219, 2015.

[18] F. El-Akhal, R. Guemmouh, S. Maniar et al., "Larvicidal activity of essential oils of Thymus vulgaris and Origanum majorana (Lamiaceae) against the malaria vector Anopheles labranchiae (diptera: Culicidae)," International Journal of Pharmacy and Pharmaceutical Sciences, vol. 8, no. 3, pp. 372-376, 2016.

[19] O. Himmi, M. Dakki, B. Trari et al., "Les Culicidae du Maroc, clé d'identification avec données biologiques et écologiques," Travaux Institut Scientifiques, Série Zoologie, vol. 44, 1995 ISSN 0252-9343.

[20] J. Brunhes, A. Rhaim, B. Geoffroy et al., Les moustiques de l'Afrique méditerranéenne. Logiciel d'identification et d'enseignement, IRD \& IPT, CD-Rom collection didactique, Éditions IRD, Montpellier, France, 2000.

[21] W. S. Abbott, "A method of computing the effectiveness of an insecticide," Journal of Economic Entomology, vol. 18, no. 2, pp. 265-267, 1925.

[22] M. Giner, C. Vassal, Z. Kouaik et al., WinDL Software Version 2.0, CIRAD-CA. URBI/MABIS, Montpellier, France, 1999.

[23] K. Smigielski, R. Prusinowska, A. Stobiecka, A. KunickaStyczyñska, and R. Gruska, "Biological properties and chemical composition of essential oils from flowers and aerial parts of lavender (Lavandula angustifolia)," Journal of Essential Oil Bearing Plants, vol. 21, no. 5, pp. 1303-1314, 2018.

[24] G. D. K. Babu, V. Thakur, and B. Singh, "Variability in the composition ofLavandula angustifoliaExtracts due to extraction methods," Journal of Herbs, Spices \& Medicinal Plants, vol. 22, no. 2, pp. 173-182, 2016.

[25] S. de Rapper, A. Viljoen, and S. van Vuuren, "The in vitro antimicrobial effects of Lavandula angustifolia essential oil in combination with conventional antimicrobial agents," Evidence-Based Complementary and Alternative Medicine, vol. 2016, Article ID 2752739, 9 pages, 2016.

[26] D. Dris, F. Tine-Djebbar, and N. Soltani, "Lavandula dentataEssential oils: chemical composition and larvicidal activity AgainstCuliseta longiareolataandCulex pipiens(Diptera: Culicidae)," African Entomology, vol. 25, no. 2, pp. 387-394, 2017.

[27] R. de.P. Martins, R. A. da S. Gomes, A. C. G. Malpass et al., "Chemical characterization of Lavandula dentata L. Essential oils grown in Uberaba-MG," Ciencia Rural, vol. 49, no. 8, 2019.

[28] I. Dammak, Z. Hamdi, S. Kammoun El Euch et al., "Evaluation of antifungal and anti-ochratoxigenic activities of Salvia officinalis, Lavandula dentata and Laurus nobilis essential oils and a major monoterpene constituent 1,8-cineole against Aspergillus carbonarius," Industrial Crops and Products, vol. 128, pp. 85-93, 2019.

[29] Y. Ez zoubi, D. Bousta, and A. Farah, "A Phytopharmacological review of a Mediterranean plant: Lavandula stoechas L," Clinical Phytoscience, vol. 6, no. 9, 2020.

[30] R. Pavela and M. Govindarajan, "The essential oil from Zanthoxylum monophyllum a potential mosquito larvicide with low toxicity to the non-target fish Gambusia affinis," Journal of Pest Science, vol. 90, no. 1, p. 369, 2016.

[31] R. Pavela, "Essential oils for the development of eco-friendly mosquito larvicides: a review," Industrial Crops and Products, vol. 76, pp. 174-187, 2015.

[32] R. Pavela, "Larvicidal property of essential oils against Culex quinquefasciatus Say (Diptera: Culicidae)," Industrial Crops and Products, vol. 30, no. 2, pp. 311-315, 2009.

[33] M. A. Tabari, M. R. Youssefi, A. Esfandiari, and G. Benelli, "Toxicity of $\beta$-citronellol, geraniol and linalool from Pelargonium roseum essential oil against the West Nile and filariasis vector Culex pipiens (Diptera: Culicidae)," Research in Veterinary Science, vol. 114, pp. 36-40, 2017.

[34] A. Michaelakis, V. P. Vidali, D. P. Papachristos et al., "Bioefficacy of acyclic monoterpenes and their saturated derivatives against the West Nile vector Culex pipiens," Chemosphere, vol. 96, pp. 74-80, 2014.

[35] G. M. Fujiwara, V. Annies, C. F. de Oliveira et al., "Evaluation of larvicidal activity and ecotoxicity of linalool, methyl cinnamate and methyl cinnamate/linalool in combination against Aedes aegypti," Ecotoxicology and Environmental Safety, vol. 139, pp. 238-244, 2017.

[36] R. Pavela, "Acute toxicity and synergistic and antagonistic effects of the aromatic compounds of some essential oils against Culex quinquefasciatus Say larvae," Parasitology Research, vol. 114, no. 10, pp. 3835-3853, 2015.

[37] B. S. Badreddine, E. Olfa, D. Samir, C. Hnia, and B. J. M. Lahbib, "Chemical composition of Rosmarinus and Lavandula essential oils and their insecticidal effects on Orgyia trigotephras (Lepidoptera, Lymantriidae)," Asian Pacific Journal of Tropical Medicine, vol. 8, no. 2, pp. 98-103, 2015.

[38] S. Sérgio, "Sistemas agrícolas e adubação na biomassa e óleo essencial de lavanda (Lavandula dentata L.)," Tese (Doutorado em Agronomia)-Curso de pós-graduação em Agronomia, Universidade Federal de Uberlândia, Uberlândia, Brazil, 2015. 